\title{
O RECONHECIMENTO DA ATIVIDADE AGRÍCOLA PARA A APOSENTADORIA
}

\author{
Natércia Daniela Alflen* ${ }^{1}$
}

\section{RESUMO}

O presente trabalho tem o objetivo de mostrar as dificuldades do reconhecimento da atividade agrícola dos segurados para a concessão de aposentadoria, tendo em vista os óbices no processo administrativo e processo judicial, quais sejam: se é permitido somente prova testemunhal para comprovar período rural, se o trabalho agrícola é considerado antes dos 12 (doze) anos de idade, se é necessário estar no campo da DER (data de entrada de requerimento). Sendo utilizado o método dedutivo para a presente pesquisa, o qual parte de uma afirmação geral para as especificidades com base na legislação, jurisprudência e doutrina.

Palavras-chave: atividade agrícola; aposentadoria; dificuldades; processo; reconhecimento.

\section{THE RECOGNITION OF AGRICULTURAL ACTIVITY FOR RETIREMENT}

\begin{abstract}
This work aims to show the difficulties of recognizing the agricultural activity of the insured for the granting of retirement, in view of the obstacles in the administrative and judicial proceedings, namely: if only testimonial evidence is allowed to prove rural period, if agricultural work is considered before the age of 12 (twelve) if it is necessary to be in the field of the DER (requeriment entry date). Using the deductive method for this research, which starts from a general vision for the specifics based on legislation, jurisprudence and doctrine.
\end{abstract}

Key Words: agricultural activity; difficulties; process; recognition; retirement.

\section{INTRODUÇÃO}

É notória a grande quantidade de trabalhadores rurais em uma região agrícola, fato levado em consideração na escolha do tema, assim analisa-se qual o impacto do reconhecimento do labor rural em concessões de aposentadorias.

Dessa maneira, este estudo é direcionado para o segurado especial, ou seja, aquele que trabalhou no campo, bem como para advogados que trabalham e pesquisam sobre o tema, pois tem assuntos corriqueiros quando se fala em considerar o trabalho agrícola para aposentar-se.

\footnotetext{
* Advogada, pós graduada em Processo Civil e Direito Previdenciário dela Faculdade Damásio de Jesus e Mestranda em Direito pela IMED. natercialflen@gmail.com
} 
O tema do presente estudo é o reconhecimento do trabalho campesino, como em muitas situações no direito isso depende de provas, o artigo 106 da Lei 8.213/91 elenca provas materiais de forma exemplificativa, porém, muitas destas provas são valoradas de maneira diferente, perante ao Instituto Nacional de Seguro Social (INSS) e a Justiça.

Além disso, esse estudo tem por objetivo analisar as dificuldades e consequentes indeferimentos do reconhecimento do período rural para a aposentadoria, sendo que na maioria das vezes há provas robustas o suficiente para a concessão do benefício.

Neste caso destaca-se que há dificuldades de comprovação do trabalho rural, pois mesmo com prova material e testemunhal significativa nos processos, o INSS profere decisão contrária. Assim, muitos segurados têm que recorrer ao Poder Judiciário para que haja reconhecimento do período agrícola para fins previdenciários.

Os temas a serem abordados na presente pesquisa descrevem sobre algumas peculiaridades do reconhecimento de trabalho campesino, por exemplo se é possível considerar trabalho rural somente com prova testemunhal, se há viabilidade de reconhecimento do trabalho rural antes dos 12 (doze) anos de idade, e se é necessário estar residindo em meio rural na DER (data de entrada de requerimento).

Destaca-se que até 31/10/1991 os segurados especiais estavam isentos de indenizar a Previdência Social para inclusão de período rural, bastava comprovar que houve atividade. A partir das disposições do artigo 45-A da Lei 8.213/91 passaram a exigir contribuições para inclusão o do labor rural.

O objetivo da pesquisa é demonstrar que existem diferenças praticas entre o processo administrativo e judicial previdenciário, as quais repercutem inclusive no reconhecimento ou não da atividade agrícola.

Diante disso, ao analisar a lei e a jurisprudência verifica-se que o tema é amplo e paradoxal ao mesmo tempo, mas ao mesmo tempo muito importante, pois esse período de atividade agrícola pode significar/repercutir na aposentadoria do segurado.

\section{PROCESSO PREVIDENCIÁRIO ADMINISTRATIVO E JUDICIAL}

É muito raro o INSS (Instituto Nacional de Seguro Social) conceder voluntariamente uma aposentadoria pelo grande número de segurados. 
Então todo processo de aposentadoria ou de requerimento de outro benefício perante ao INSS exige um requerimento formal, e essa fase se chama administrativa.

Se o processo ou benefício é deferido, termina ali, porém se houver indeferimento pode ser feito recurso ainda na fase administrativa ou pode partir para a fase judicial. Desta forma, toda fase judicial pressupõem uma fase administrativa, pois todo o processo realizado no INSS será analisado novamente pelo juízo.

\subsection{Processo Administrativo}

O processo administrativo possui seus próprios princípios, sendo norteados pelo art.

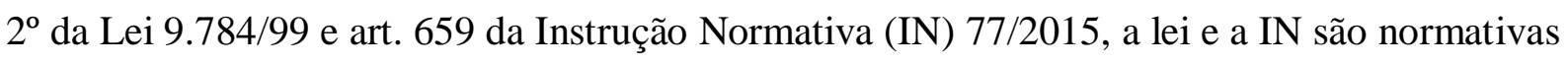
extremamente importantes e devem fundamentar o requerimento feito perante a Autarquia federal (INSS). Jurisprudências e a Lei 8.213/91 devem servir de base para as petições judiciais.

Além disso, a Constituição Federal de 1988 contemplou o devido processo legal no seu elenco de direitos e garantias fundamentais ao dispor que ninguém será privado da lei ou de seus bens sem o devido processo legal (art. $5^{\circ}, \mathrm{LVI}$ ). Ademais consagrou expressamente os direitos ao contraditório e ampla defesa, bem como ao uso de recursos, em processo judicial ou administrativo (art. $5^{\circ}$ LV) (MAUSS e TRICHES, 2017, p. 36).

O requerimento no processo administrativo é muito importante, uma vez que servirá de base para o requerimento judicial posteriormente, por isso deve ser bem instruído, com provas que dão suporte ao pleito e não simplesmente um requerimento formal e padrão para todos e qualquer benefício, só para ter o indeferimento e partir para a seara jurídica.

Além disso, o processo administrativo deve ter as condições exigidas pelo artigo 673 da Instrução Normativa (IN 77/2015).

Todos os elementos citados no artigo são importantes na composição do processo administrativo, porém mais importante do que isso são os princípios, quais sejam: princípio do contraditório e da ampla defesa, da motivação, da segurança jurídica, da oficialidade, da legalidade, da gratuidade, da informalidade, da boa-fé, do devido processo legal. (BRASIL, 1999). Tais princípios devem ser respeitados e, portanto, nortear todo o processo e decisão.

A partir do requerimento realizado diante da autarquia será proferida uma decisão de deferimento/concessão ou indeferimento/não concessão do benefício. Como já mencionado 
essa fase é a administrativa, que tem por base os princípios e normas da IN 77/2015, depois desta fase, pode se optar por seguir na via administrativa interpondo recurso ou partir para a seara judicial e discutir o direito perante a esfera judicial,

O trecho da obra do autor e juiz, citado a seguir, esclarece sobre a fase administrativa e judicial que compõem o processo previdenciário. Com o indeferimento administrativo deflagra-se uma controvérsia que abre ao particular dois caminhos: a interposição de recurso administrativo ou a invocação de tutela jurisdicional. (SAVARIS, 2014).

Ainda na fase administrativa muito se utiliza a J.A.(justificação administrativa), uma espécie de audiência, realizada pela Agência da Previdência Social, na qual serão ouvidas o autor, também conhecido como justificante e as suas testemunhas a fim de comprovar os fatos e documentos que compuseram os autos do processo.

Evidencia-se que somente será admitido o processamento de J.A. na hipótese de ficar comprovado a inexistência de outro meio capaz de configurar a verdade do fato alegado, e o início de prova material apresentado levar à convicção do que se pretende comprovar (AGOSTINHO e GOUVEIA, 2015, p. 85)

Como mencionado, a J.A. só será autorizada se houver documentos capazes de autorizá-la, pois no processo administrativo não se admite prova exclusivamente testemunhal, salvo caso fortuito ou força maior, ela deve ser utilizada como subsidiária. Mais adiante essa peculiaridade do processo administrativo ficará mais clara.

Como não poderia deixar de ser o processo administrativo sofre profundas influências dos preceitos constitucionais tais como o devido processo legal, a ampla defesa, o contraditório, e tantos outros princípios que devem ser respeitados a fim de que esse procedimento seja válido. Além disso, sofre a influência da disciplina estatuída pela Lei 9.784/99, pela jurisprudência. (MAUSS e TRICHES, 2017, p. 36-37)

Apesar de subsidiária a prova oral é importante na composição do processo administrativo sendo analisada de uma forma ampla para a configuração do trabalho rural do segurado.

\subsection{Processo Judicial}


Importante referir que o requerimento judicial com mesmas partes, mesmo pedido pressupõe desistência do recurso administrativo, ou seja, não é possível discutir o mesmo direito na Autarquia e Justiça em tempo igual.

O processo judicial com demanda previdenciária, em regra, deve ser proposto na Justiça Federal, pois tem como parte uma autarquia federal INSS - Instituto Nacional do Seguro Social, o inciso I do artigo 109 da Constituição Federal de 1988 refere, que é de competência da justiça federal julgar as causas em que é parte o INSS.

$\mathrm{O} \S 3^{\circ}$ do mesmo artigo, 109 da CF/88 aduz sobre a competência delegada, sendo assim, os casos em que pode ser utilizada a Justiça Estadual para demandas em que o INSS é parte.

Porém a EC 103/2019 (Emenda Constitucional) alterou a previsão, antes o autor poderia optar entre a justiça federal ou estadual se não tinha justiça federal na comarca, hoje, depois da EC/2019 ficou restringida a competência delegada previdenciária da justiça estadual às causas ajuizadas em comarcas de domicílio do segurado situadas a mais de setenta quilômetros da sede de vara federal. (SOUZA, 2019).

Seja na justiça federal ou estadual o processo judicial é muito mais abrangente que o previdenciário/administrativo, permitindo, ou melhor, considerando as provas de uma maneira mais democrática, pois é possível afirmar que há uma imparcialidade maior no âmbito judicial, uma vez que quem julga não é o mesmo órgão que vai ter que arcar financeiramente com a demanda.

Destaca-se que o juiz considera o conjunto robusto de prova constituído nos autos do processo seja a prova material ou testemunhal, serão analisadas de forma global.

Pode se dizer também que muitas vezes o que é óbice para o INSS em âmbito administrativo não é considerado fato relevante para o juiz federal ou estadual.

É fato que o processo administrativo é base para o judicial, tanto que o primeiro ato do juiz é requerer ao INSS a juntada do processo administrativo para prosseguimento do feito, a fim de comprovar que houve processo e quais foram as razões do indeferimento.

\section{O RECONHECIMENTO DO PERÍODO RURAL E SUAS PECULIARIDADES}


É possível aposentar-se e considerar o período rural em três modalidades de acordo com o ordenamento jurídico atual brasileiro, quais sejam, aposentadoria por idade rural, aposentadoria por tempo de contribuição e aposentadoria híbrida.

$\mathrm{Na}$ aposentadoria por idade rural exige-se 55 anos de idade para a mulher e 60 anos para o homem, sendo 15 anos de carência, ou seja, o segurado tem que comprovar que trabalhou ao menos 15 anos na lavoura, de acordo com o $\S 1^{\circ}$ do artigo 48 da Lei 8.213/91 (BRASIL, 1991)

Já a aposentadoria por tempo de contribuição exige 30 anos de tempo de serviço para a mulher e 35 anos para o homem, nesta modalidade independe a idade, ou seja, se completou o tempo de serviço exigido a aposentadoria é concedida. Além disso, é permitido somar o tempo rural e o urbano para completar o tempo de contribuição. (BRASIL, 1991)

E, a aposentadoria híbrida exige 65 anos de idade para o homem em e 62 anos para a mulher e ainda 15 anos de carência trabalhados no campo e na cidade, pois permite somar os dois períodos distintos até obter os 15 anos, conforme artigo 48 da Lei 8.213/91 (BRASIL, 1991)

A aposentadoria híbrida surgiu com a lei 11.718/08 que alterou a lei 8.213/91 com o objetivo de abranger os agricultores que vieram do campo para a cidade com o êxodo rural. $\mathrm{O}$ conceito de êxodo rural de uma maneira geral é a migração do campo para a cidade.

O desencadeamento do êxodo rural é consequência, entre outros fatores, da implantação de relações capitalistas modernas na produção agropecuária, onde o modelo econômico privilegia os grandes latifundiários e a intensa mecanização das atividades rurais expulsa os pequenos produtores do campo. $\mathrm{O}$ intenso processo de mecanização das atividades agrícolas tem substituído a mão de obra humana. Os pequenos produtores que não conseguem mecanizar sua produção têm baixo rendimento de produtividade, o que os coloca em desvantagem no mercado. (FRANSISCO, 2020).

Como referido, o êxodo rural é consequência do capitalismo e da mecanização do agronegócio, que apesar de facilitar o trabalho no campo substituiu as pessoas as pessoas foram sendo substituídas pelas máquinas e esses trabalhadores acabaram indo buscar emprego na cidade e consequentemente residir no meio urbano.

Destaca-se que na aposentadoria híbrida, ou em qualquer outra que abrange o período rural é direcionada para o pequeno produtor rural. 
Ser pequeno produtor rural é exigência em todas as modalidades de aposentaria descritas anteriormente, sendo que pequeno produtor é aquele que vive em regime de economia familiar, o que significa referir que a atividade é essencial para o grupo familiar, que o sustento principal da família provem dos produtos que colhem no trabalho exercido na agricultura, mais especificamente plantam para comer, e vendem somente o excedente da produção.

Quando se menciona regime de economia familiar deve prevalecer o trabalho manual, sem máquinas para a realização do serviço pesado, pois costumeiramente se questiona isso, pois quer dizer que se tem máquinas subentende-se que a propriedade é maior do que os 04 (quatro) módulos fiscais permitidos pela lei 8.213/91. (BRASIL, 1991)

Essas peculiaridades do pequeno produtor rural, quais sejam, que a agricultura deve ser exercida em regime de economia familiar que limitam o tamanho da propriedade em 04 (quatro) módulos fiscais, e que não permite possuir empregados trabalhando em sua lavoura por mais de 120 dias, estão no artigo 11 , inciso $\mathrm{V}$, alínea “a” e $\S \S 1^{\circ}, 7^{\circ}$ da lei 8.213/91.

Salienta-se que o valor do módulo fiscal varia de região para região. Na nossa região, planalto médio do Rio Grande do Sul, 01 (um) módulo fiscal corresponde a 20 ha (hectares), portanto 04 (quatro) módulos fiscais são 80ha. Desta forma, 80ha é o limite estabelecido pela legislação. (EMBRAPA, 2020)

\subsection{A prova testemunhal isolada é suficiente para comprovar período de atividade agrícola?}

Como já referido, não se admite prova exclusivamente testemunhal para comprovar um fato referente a trabalho agrícola no processo administrativo quando se trata de concessão de aposentadoria.

Se o segurado especial, trabalhador agrícola, comprovar que trabalhou na agricultura até o ano de 1991 não é exigido contribuição, apenas comprovar que houve de fato e exercício labor rural. Contudo, muitos segurados imaginam que basta afirmar perante o servidor do INSS que trabalhou na zona rural que haveria o reconhecimento de serviço rural e por conseguinte aposentadoria.

Mas não é bem assim, para reconhecimento de labor rural, há uma série de requisitos e início de prova material para dar início ao processo administrativo. 
O parágrafo único do artigo 227 do Código Civil atual aduz que a prova testemunhal é utilizada como subsidiária. Art. 227. [...] Parágrafo único. Assim, qualquer que seja o valor do negócio jurídico, a prova testemunhal é admissível como subsidiária ou complementar da prova por escrito. (BRASIL, 2015)

Desta forma, para comprovar um fato no direito provas materiais/documentais são essenciais, pois a prova testemunhal é utilizada como subsidiária, portanto complementa a prova material.

Além disso, a súmula 149 do STJ reforça essa compreensão “A prova exclusivamente testemunhal não basta à comprovação da atividade rurícola, para efeito da obtenção de benefício previdenciário.” (BRASIL, 1995).

Neste mesmo sentido é o seguinte julgado do TRF da $1^{\text {a }}$ Região:

\begin{abstract}
APELAÇÃO CÍVEL. PREVIDENCIÁRIO. APOSENTADORIA RURAL POR IDADE. AUSÊNCIA DE PROVA DOCUMENTAL. DEPOIMENTO TESTEMUNHAL. SÚMULAS 149/STJ e 27/TRF-1 ${ }^{a}$ REGIÃO. REQUISITOS LEGAIS NÃO PREENCHIDOS. CONCESSÃO INDEVIDA.1. Ausente início razoável de prova material, pois o único documento juntado aos autos é a carteira de filiação ao sindicato de trabalhadores rurais, que não pode ser considerado como início de prova material [...] 2.A producão de prova exclusivamente testemunhal é insuficiente à comprovação da atividade rurícola para efeito da obtenção de benefício previdenciário, nos termos das Súmulas 149 do STJ e 27 deste Tribunal. 3. A parte autora não faz jus ao benefício de aposentadoria rural por idade, previsto nos arts. 143 e 11, VII, ambos da Lei 8.213/91, porquanto as provas documentais produzidas nos autos não foram suficientes para demonstrar a sua condicãa de rurícola. 4. Apelação provida para, reformando a sentença, julgar improcedente o pedido. (TRF1, Processo $\mathrm{n}^{\circ}$ 0045032-62.2010.4.01.9199/MT, Rel. Des. Kàssio Marques, Julg.: 30/05/2012, eDJF1: 11/07/2012). (grifo nosso)
\end{abstract}

Sendo assim, a prova testemunhal sozinha não é capaz de caracterizar a condição de segurado especial, ou seja, considerar que houve trabalho rural desenvolvido na lavoura pelo segurado. No processo administrativo a prova testemunhal possuí caráter complementar e subsidiário.

A J.A., justificação administrativa, como é chamada a audiência na seara administrativa só é autorizada com um mínimo de provas materiais e, ainda, se o INSS não se convenceu que houve de fato trabalho agrícola.

Desta maneira, a inquirição das testemunhas para comprovação de período agrícola deve ser requerida com muita cautela, bem como saber "escolher" quem são as pessoas que 
podem ser testemunhas, o ideal é que sejam vizinhos e que tenham visto o justificante trabalhando na atividade campesina.

Muitos autores ratificam essa afirmação pois a prova testemunhal pode se corromper facilmente e muitas vezes é indicada para contribuir com a prova documental e assim comprovar que de fato o segurado trabalhou, mas também pode ocorrer o contrário “[...] a prova testemunhal é a pior prova que existe, sendo considerada a prostituta das provas, justamente por ser a mais insegura.”(MARTINS, 2010, p. 336).

A prova testemunhal é um instrumento muito importante para comprovar que o segurado se enquadra na condição de segurado especial, e mais do que isso, quando não é possível comprovar através de documentos todo o período requerido a prova testemunhal tem o condão de abranger de maneira mais significativa e assim caracterizar o trabalho agrícola para a aposentadoria.

\subsection{A (im)possibilidade de considerar a atividade agrícola antes dos 12 anos de idade}

Destaca-se que a norma constitucional descrita prevê no artigo $7^{\circ}$, inciso XXXIII da Constituição Federal a "proibição de trabalho noturno, perigoso ou insalubre a menores de dezoito e de qualquer trabalho a menores de dezesseis anos, salvo na condição de aprendiz, a partir de quatorze anos". Ou seja, tal norma proíbe o trabalho noturno, perigoso ou insalubre a menores de dezoito e de qualquer trabalho a menores de dezesseis anos, salvo na condição de aprendiz, a partir de quatorze anos; tem caráter protecionista.

Essa norma visa coibir o trabalho infantil, não podendo servir, porém, de restrição aos direitos do trabalhador no que concerne à contagem de tempo de serviço para fins previdenciários.

Assim, em regra, o INSS adotava o entendimento de considerar o período de labor rural a partir dos seus 12 anos de idade até outubro de 1991, ou seja, o trabalho rural antes dos 12 anos de idade não gerava efeitos previdenciários, sendo considerado mera colaboração.

Todavia, o julgamento no agravo interno no agravo em recurso especial $\mathrm{n}$. 956.558/SP, o STJ adotou entendimento diverso da Autarquia Federal, e considerou o trabalho do menor de 12 anos no meio rural.

Essa decisão reconheceu cômputo excepcional de trabalho antes dos 12 anos para fins 
previdenciários com influência de pensamentos garantísticos e com entendimento jurídico de maior proteção e mais eficaz tutela dos direitos subjetivos dos hipossuficientes. (MAIA, 2016).

A decisão citada anteriormente abriu precedente para que outros segurados também pudessem obter esse reconhecimento de trabalho rural antes dos 12 anos de idade, desde que tivessem provas afim de ensejar início de prova material.

Apesar da Constituição Federal, conforme previsão do artigo $7^{\circ}$, XXXIII, não reconhecer trabalho de menor de 16 anos, o voto entendeu o Ministro entendeu, a partir da análise de seu voto que esse artigo não pode ser interpretado de maneira a prejudicar a criança ou o adolescente, não podendo assim ser utilizada para privá-los de seus direitos (RE 537.040/SC Rel. Min. DIAS TOFFOLI, Dje 9.8.2011) (MAIA, 2016).

Não obstante as normas protetivas às crianças o trabalho infantil ainda se faz presente no seio da sociedade. São inúmeras a crianças que desde a tenra idade são levadas ao trabalho pelos seus próprios pais para auxiliarem no sustento da família, colocadas geralmente em atividades domésticas e rurais (MAIA, 2016)

Assim, não há como desconsiderar a gama expressiva de pessoas, nos termos do artigo 11 da lei 8.213/91, apesar de se enquadrarem como segurados obrigatórios possuem idade inferior aquelas prevista constitucionalmente e não tem a respectiva proteção previdenciária. (MAIA, 2016).

Assim, apesar da limitação do trabalho do infante fixar no art. $7^{\circ}$ XXXIII CF/88 não há como fixar qualquer limite etário, pois a adoção de idade mínima enseja dupla punição, como já mencionado, perda de plenitude da infância e não reconhecimento por parte do INSS deste trabalho efetivamente ocorrido. Sendo assim, tem que analisar o caso concreto sem estabelecer idade mínima. (MAIA, 2016).

Em outras palavras, compromete não somente o desenvolvimento físico e emocional, mas também preparo profissional necessário a se obter melhor colocação no mercado de trabalho, além de não reconhecimento do labor para fins previdenciários. (MAIA, 2016).

Conclui-se, portanto, que é vedado o trabalho infantil, mas o trabalho rural realizado antes dos 12 anos não pode ser desconsiderado sob pena de punir duplamente o trabalhador que teve sua infância sacrificada por conta do trabalho na atividade rural e não poderia ter tal tempo computado no momento de sua aposentadoria. 
Apesar de parecer pequeno o tempo (considerar trabalho antes dos 12 anos de idade com consequências previdenciárias) esse período pode ser decisivo para a aposentadoria ou não de um segurado.

A decisão jurisprudencial, a seguir colacionada aduz que é possível reconhecimento de período rural trabalhado antes dos 12 anos de idade, desde que comprovado.

PREVIDENCIÁRIO. LABOR URBANO REALIZADO POR MENOR DE IDADE
INFERIOR A DOZE ANOS. RECONHECIMENTO PARA FINS
PREVIDENCIÁRIOS. FINALIDADE PROSPECTIVA-PROTETIVA DA
NORMA. SÚMULA No 5/TNU. QUESTÃO DE ORDEM N. 20/TNU.
INCIDENTE PROVIDO. - Trata-se de incidente de uniformizacão movido pela
parte autora em face de Acórdão da Turma Recursal que julgou parcialmente
procedente o pedido de anulacão de revisão administrativa do benefício de
aposentadoria, declaracão de trabalho menor de 12 anos e condenação à
devolucão dos descontos indevidamente realizados e danos morais. $[\ldots]$ Como
se vê entender de forma diversa acaba por contrariar a maciça jurisprudência
de nossos tribunais que há muito entendem que os menores de idade (12 anos)
não podem ser prejudicados em seus direitos trabalhistas e previdenciários,
desde que comprovado o efetivo labor. […] (TNU - PEDILEF:
00021182320064036303, Relator: JUIZ FEDERAL FREDERICO AUGUSTO
LEOPOLDINO KOEHLER, Data de Julgamento: 14/04/2016, Data de Publicação:
10/06/2016) (grifo nosso)

Assim, pode-se considerar trabalho rural antes dos 12 anos de idade, uma vez comprovado, pois não seria justo ter sua infância prejudicada com o trabalho e ainda esse período não ser considerado para fins previdenciários, como já referido, seria uma dupla punição ao segurado que é vítima do sistema.

A súmula 05 da TNU (Turma Nacional de Uniformização) é neste mesmo sentido “A prestação de serviço rural por menor de 12 a 14 anos, até o advento da Lei 8.213, de 24 de julho de 1991, devidamente comprovada, pode ser reconhecida para fins previdenciários". (BRASIL, 2016)

Destaca-se inclusive a súmula 577 do STJ, a qual autoriza o reconhecimento de labor rural anterior ao documento mais antigo, desde que baseado em convincente prova testemunhal. "É possível reconhecer o tempo de serviço rural anterior ao documento mais antigo apresentado, desde que amparado em convincente prova testemunhal colhida sob o contraditório.” (BRASIL, 2016)

Assim sendo, pode-se concluir esse tópico afirmando que é possível reconhecimento de trabalho rural antes dos 12 anos de idade e inclusive com reflexos na aposentadoria, mesmo que não possua documentos do referido período, pois pode ser considerado através de prova testemunhal, máxime por que se o contrário fosse verdadeiro haveria punição em dose 
dupla, pois de fato sua infância fora devastada pelo trabalho rural e ainda não haveria consideração do trabalho realizado quando deveria estar estudando e/ou brincando. Desta forma, é justo o reconhecimento do trabalho rural, mesmo que anterior aos 12 anos de idade, desde que devidamente comprovado de forma material (documentação) e com testemunhas.

\section{3 É necessário estar residindo no campo na DER (data de entrada de requerimento)?}

Depois de muitos anos residindo e trabalhando no campo muitos segurados resolvem ir residir na cidade, mas quem reside na cidade pode requer aposentadoria rural? Todo o período trabalhado no campo será em vão?

Esses indivíduos que resolveram residir na cidade não podem ter seu direito a aposentadoria rural impedido somente pelo fato de na data de entrada do requerimento, a chamada DER, não estarem mais desenvolvendo atividade agrícola no campo.

De um modo geral, as decisões administrativas quanto ao período rural, principalmente no caso de aposentadoria por idade rural (que a carência deve se referir aos últimos 15 anos) exigem que o segurado esteja residindo no campo por afirmarem que somente assim preservam a qualidade de segurado.

Qualidade de segurado quando se trata de segurado urbano é estar contribuindo para ter direito a aposentadoria, já no segurado rural como não se exige contribuição, o entendimento da Autarquia Federal é de que os rurais mantêm a qualidade de segurado morando e trabalhando no campo.

Muitas vezes mesmo com prova material e testemunhal robusta, o INSS não considera o período de segurado especial do trabalhador, pois afirma que para o deferimento desta modalidade de aposentadoria é necessário que o trabalho agrícola seja imediatamente anterior ao requerimento administrativo, com base na a súmula 54 da TNU:

Súmula 54: Para concessão de aposentadoria por idade de trabalhador rural, $\underline{\mathbf{0}}$ tempo de exercício de atividade equivalente à carência deve ser aferido no período imediatamente anterior ao requerimento administrativo ou à data do implemento da idade mínima. (BRASIL, 2012). (grifo nosso). (BRASIL, 2012)

Ou seja, quando for fazer o requerimento administrativo o período rural deve ser imediatamente anterior a DER (data de entrada do requerimento), é o que menciona o artigo 
39, I da lei 8.213/91:

Art. 39. Para os segurados especiais, referidos no inciso VII do caput do art. 11 desta Lei, fica garantida a concessão:

I - de aposentadoria por idade ou por invalidez, de auxílio-doença, de auxílioreclusão ou de pensão, no valor de 1 (um) salário mínimo, e de auxílio-acidente, conforme disposto no art. 86 desta Lei, desde que comprovem o exercício de atividade rural, ainda que de forma descontínua, no período imediatamente anterior ao requerimento do benefício, igual ao número de meses correspondentes à carência do benefício requerido, observado o disposto nos arts. 38-A e 38-B desta Lei; (grifo nosso).

Desta forma, entende-se que não é possível reconhecimento de labor rural com reconhecimento do tempo remoto ou descontínuo, ou ainda, se o período imediatamente anterior a data de entrada de requerimento não corresponder ao último.

Contudo, o tema 131 da TNU afirma:

Tese Firmada: Para a concessão da aposentadoria por idade híbrida ou mista, na forma do art. 48, $\S 3^{\circ}$, da Lei n. 8.213/91, cujo requisito etário é o mesmo exigido para a aposentadoria por idade urbana, é irrelevante a natureza rural ou urbana da atividade exercida pelo segurado no período imediatamente anterior à implementação do requisito etário ou ao requerimento do benefício. Ainda, não há vedação para que o tempo rural anterior à Lei 8.213/91 seja considerado para efeito de carência, mesmo que não verificado o recolhimento das respectivas contribuições. (24/11/2016). (PEDILEF 5009416-32.2013.4.04.7200/ SC) - Tema 131. (BRASIL, 2017) (grifo nosso)

Sendo assim, quando se trata de aposentadoria híbrida por idade deve-se apenas somar o tempo de labor rural e o tempo de trabalho urbano.

No mesmo sentido o STJ estabelece jurisprudência de que a aposentadoria híbrida deve ser concedida "mediante a mescla de períodos laborados em atividade rural e urbana, não importando qual seja a atividade exercida pelo segurado ao tempo do requerimento administrativo ou do implemento do requisito etário" (CJF, 2014).

Assim sendo, não é necessário estar residindo no campo para que o tempo rural para fins de aposentadoria seja caracterizado, uma vez que o labor campesino foi exercido em período anterior ao do requerimento e o fato de não estar residindo no campo no momento do requerimento não pode prejudicar o trabalhador rural.

\section{CONCLUSÃO}


Através da presente pesquisa conclui-se que para comprovar período rural para fins de aposentadoria é necessário primeiro fazer um processo administrativo e se este for indeferido discutir o direito na esfera judicial.

Conforme visto, as provas apresentadas no INSS e na justiça no Poder Judiciário são consideradas de maneira diferente, por exemplo, se apresentar inscrição no sindicato dos trabalhadores e certificado escolar que estudou na localidade onde trabalhava na Autarquia essa prova não é suficiente para caracterizar período rural e nem mesmo para autorizar prova testemunhal, pois não mostra início de prova material, já na esfera jurídica com as mesmas provas o requerimento para considerar o tempo rural é deferido. É, pois, isso que a maioria dos pedidos de aposentadoria com tempo rural recorrem ao Poder Judiciário para serem caracterizados.

Ao longo da pesquisa apresentou-se quais são as modalidades de aposentadoria que permitem contabilizar o tempo agrícola, quais sejam, aposentadoria por idade rural, por tempo de contribuição e por fim, aposentadoria híbrida.

Como vimos no decorrer do trabalho não é admitido somente prova testemunhal para comprovar o período rural é necessário início de prova material, de acordo com a súmula 149 da TNU e precedentes jurisprudenciais.

Além disso, também verificou-se que é possível considerar trabalho campesino antes dos 12 (doze) anos de idade, desde que a prova documental e a testemunhal sejam idôneas e harmônica, entre si, pois não seria coerente que o menor, o qual não pode usufruir de sua infância também tenha que abrir mão de seus direitos previdenciários.

Outra questão discutida no trabalho foi sobre a exigência de o segurado estar residindo no campo na DER (data de entrada de requerimento), sendo que a Autarquia entende ser necessário, por preservar a qualidade de segurado, já se o mesmo direito é discutido na esfera judicial não se exige como pré-requisito estar residindo na cidade.

Por fim, assevera-se que os temas trazidos à tona na presente pesquisa são assuntos corriqueiros e por isso pertinentes para quem pretende considerar período agrícola para fins previdenciários e até mesmo para advogados que estudam e trabalham com o tema.

Então, a partir da pesquisa realizada prova material é requisito para caracterizar trabalho agrícola, não é permitido comprovar somente com prova testemunhal, não é necessário estar residindo no campo para requerer que o tempo de labor rural seja considerado 
para fins previdenciários e ainda é possível contabilizar período agrícola antes dos 12 anos de idade para a aposentadoria.

\section{REFERÊNCIAS BIBLIOGRÁFICAS}

AGOSTINHO e GOUVEIA, Theodoro Vicente e Michel Oliveira. Processo Administrativo Previdenciário: Teoria e Prática. Incluindo modelos de requerimento e recursos administrativos. LTr, São Paulo; 2015.

BRASIL.Lei8.213,de24dejulhode1991.BrasíliaPresidênciaRepublica.Disponívelem: http://www.planalto.gov.br/ccivil_03/leis/18213cons.htm. Acesso em: 30 de maio de 2020.

BRASIL. Lei 9.784, de 29 de janeiro de 1999. Brasília Presidência República. Disponível em: http://www.planalto.gov.br/ccivil 03/leis/19784.htm. Acesso em: 10 de julho de 2020.

BRASIL Constituição da República Federativa do Brasil/1988. Brasília Presidência República.Disponívelem:http://www.planalto.gov.br/ccivil 03/constituicao/constituicaocompi lado.htm Acesso em: 10 de julho de 2020.

BRASIL. Instrução Normativa 77, de 21 de janeiro. de 2015. Brasília Presidência Republica.

Disponívelem:https://www.in.gov.br/materia//asset publisher/Kujrw0TZC2Mb/content/id/32 120879/do1-2015-01-22-instrucao-normativa-n-77-de-21-de-janeiro-de-2015-32120750.

Acesso em: 15 de julho de 2020.

BRASIL, EC 103/2019, 12 de novembro de 2019. Brasília Presidência República. Disponível em: http://www.planalto.gov.br/ccivil 03/constituicao/emendas/emc/emc103.htm . Acesso em: 15 de julho de 2020.

BRASIL, Lei 11.718, de 20 de junho de 2018. Brasília Presidência República. Disponível em: http://www.planalto.gov.br/ccivil 03/ ato2007-2010/2008/lei/111718.htm Acesso em 17 de julho de 2020.

EMBRAPA. Módulos Fiscais. Disponível em: https://www.embrapa.br/. Acesso em: 15 de julho de 2020.

MARTINS, Sergio Pinto. Direito processual do trabalho. Atlas. São Paulo, 2010.

MAUSS E TRICHES, Adriano e Alexandre Schumacher. Processo administrativo previdenciário eficiente. LTr. São Paulo, 2017.

SOUZA, Antônio Muniz de. Restrição à competência delegada previdenciária na justiça estadual. Disponível em: https://www.conjur.com.br/2019-nov-17/restricao-competenciadelegada-previdenciaria-justica-estadual . Acesso em 15 de julho de 2020. 
SUPERIOR TRIBUNAL DE JUSTIÇA. Súmula 149. A prova exclusivamente testemunhal não basta à comprovação da atividade rurícola, para efeito da obtenção de beneficio previdenciário.Disponívelem:https://scon.stj.jus.br/SCON/sumanot/toc.jsp?materia=\%27DIR EITO\%20PREVIDENCI\%C1RIO\%27.mat.\#TIT26TEMA0. Acesso em: 13 de julho de 2020.

SUPERIOR TRIBUNAL DE JUSTIÇA. Súmula 577. É possível reconhecer o tempo de serviço rural anterior ao documento mais antigo apresentado, desde que amparado em convincente prova testemunhal colhida sob 0 contraditório. Disponível em: https://scon.stj.jus.br/SCON/sumanot/toc.jsp?materia=\%27DIREITO\%20PREVIDENCI\%C1 RIO\%27.mat.\#TIT28TEMA0. Acesso em: 13 de julho de 2020.

TRIBUNAL REGIONAL FEDERAL $1^{\circ}$ REGIÃO. APELAÇÃO CIVIL. PREVIDENCIÁRIO. PROCESSO No 0045032-62.2010.4.01.9199. Rel. Kassio Nunes Marques. Disponível em: https://arquivo.trf1.jus.br/PesquisaMenuArquivo.asp?p1=00450326220104019199\&pA=\&pN $=450326220104019199$. Acesso em: 19 de setemnbro 2021.

TRIBUNAL NACIONAL DE UNIFORMIZAÇÃO. Rel. Frederico Augusto Leopoldino Koehler.Disponívelem:https://www.cjf.jus.br/publico/pdfs/00021182320064036303.pdf.

Acesso em: 13 de junho de 2020.

TURMA NACIONAL DE UNIFORMIZAÇÃO. Rel. Simone dos Santos Lemos Fernandes. Disponívelem:https://www.ieprev.com.br/conteudo/categoria/3/4026/a eficacia prospectiva e_retrospectiva_do_inicio_de_prova_material_nas_aposentadorias_por_idade_rural .Acesso em: 12 de julho de 2020.

TURMA NACIONAL DE UNIFORMIZAÇÃO DOS JUIZADOS ESPECIAIS FEDERAIS. Súmula 05. A prestação de serviço rural por menor de 12 a 14 anos, até o advento da Lei 8.213, de 24 de julho de 1991, devidamente comprovada, pode ser reconhecida para fins previdenciários. Disponível em: https://www.cjf.jus.br/phpdoc/virtus/sumula.php?nsul=5 . Acesso em: 05 de julho de 2020.

TURMA NACIONAL DE UNIFORMIZAÇÃO DOS JUIZADOS ESPECIAIS FEDERAIS. Súmula 54. Para a concessão de aposentadoria por idade de trabalhador rural, o tempo de exercício de atividade equivalente à carência deve ser aferido no período imediatamente anterior ao requerimento administrativo ou à data do implemento da idade mínima. Disponível em: https://www.cjf.jus.br/phpdoc/virtus/sumula.php?nsul=54. Acesso em 23 de junho de 2020. 